\title{
DYNASTIC MARRIAGE AND SUCCESSION AT TIKAL
}

\author{
Philip C. Thompson \\ University of New Orleans
}

\begin{abstract}
Use of the Colonial Yucatec Maya as an ethnohistoric analogy suggests that the Classic Maya at Tikal practiced bilateral cross cousin marriage, traced descent in both the male and female lines (double descent) and recognized both matrilineages and patrilineages. Further, Colonial Yucatec Maya inheritance patterns and kin terms suggest that the Classic Maya may have intended political office to pass alternately to matrilineal and patrilineal heirs, rather than strictly patrilineal heirs, as has been proposed (Haviland, 1977). When these rules are applied to the genealogical relationships of the rulers of Tikal proposed by Coggins (1975), the resulting diagram strongly implies that, while two or more patrilines competed for the ruling position, the line of succession was defined by a specific pair of matrilines for each 13 katun cycle.
\end{abstract}

In a recent article, William A. Haviland (1977) presents his interpretation of the kinship principles governing the dynastic succession at Tikal. His work is based on a tentative reconstruction, by Clemency Coggins (1975), of some of the genealogical relationships of the rulers of Tikal from the fourth to the ninth centuries A.D. (see Figure 1). In the following paragraphs I propose an alternative interpretation of the kinship principles underlying the Tikal succession. My views are based on a reconsideration of the Coggins diagram as well as analogies provided by the kin term and inheritance systems of the Colonial Yucatec Maya.

Haviland believes the Coggins genealogy to be evidence of a patrilineal rule of political succession. He bases this view on the 
fact that seven of the eleven successions in the genealogy are from father to son. However, a problem arises with the four remaining successions, which are from father to daughter's husband, the son-inlaw, who is obviously not a patrilineal descendant. Haviland seeks to overcome this problem by arguing that these successions to sons-in-law are attempts to maintain a patrilineal rule in the absence of a suitable male heir, a son. In fact, he contends, the true bearer of the succession is the daughter. She acts as a stand-in, a substitute, for the requisite male. Her husband, the son-in-law, is not important in the succession and usually is an outsider from somewhere other than Tikal. This line of reasoning allows him to resolve another apparent anomaly. This is the fact that, in what is supposed to be a system of patrilineal successsion, at least two women are given great importance in the stelae and tomb inscriptions. These women are linking females whose husbands are outsiders; and he argues that it is precisely because of their roles as female links in a patriline that they are given emphasis. A final obstacle to the patrilineal thesis is the fact that, in three of the four successions to sons-in-law, there are sons available to inherit the office. Haviland hypothesizes that these sons had either died or moved away.

I do not believe that the evidence presented by Haviland adequately supports the thesis that the Maya at Tikal adhered exclusively to a patrilineal rule of political succession. To my mind, the fact that as many as $36 \%$ of the successsions are not patrilineal suggests that something else is at play in the system. I am enticed into asking what other systems of descent and marriage might produce the results of Figure 1. Might it, in fact, be matrilineal descent? Or even double descent? What are the possible kin relationships of in-marrying spouses? Are they cousins? Are they unrelated? And, as an ethnohistorian working with materials pertaining to the 18th century Yucatec Maya (Thompson, 1978), I cannot avoid interpreting these successions through the prism of the Colonial Yucatec kin term and inheritance systems. What terms would an 18th century Maya in Yucatan use to describe these successions? What would he call his son, his daughter's husband, his daughter's son, his son's son, and his daughter's son's son - the five kin relationships pertaining to the succession in Figure 1? And, what do inheritance patterns in 18th century Yucatan suggest about the inheritance of political office in Classic Period Tikal?

As an ethnohistoric analogy, the Yucatec Maya provide ample support for the view that the Maya of Tikal did not trace descent 
solely in the male line. Rather, they traced it in both the male and female lines (double descent). At the time of the Spanish Conquest the Yucatec Maya had both patrilineages and matrilineages. Chibal referred to descent in the male line and was often employed in reference to one's patrilineage. Dzacab, on the other hand, referred to descent in the female line, and to one's matrilineage (Roys, 1940: 38). Furthermore, every Mayan was known by a variety of names, but salient among them were the patronymic and the matronymic or naal (op. cit. 38-48), probably a combination of $n a$ ('mother')' and al ('a woman's child'). The former was inherited from the father and, after the Conquest, it was employed as the surname in the European system. The latter, the naal name, was inherited from the mother and, though many such names were also common patronymics, it appears to have derived from the mother's "first" name, rather from her patronymic (op. cit., 37). After the Conquest the naal name ceased to be used. A similar dichotomy appears in the word for noble, almehen, which was composed of two words used for child, one by men, the other by women. Men called both their own children and their brothers' children mehen. Women employed the term al for their own offspring as well as the offspring of their sisters. When combined into almehen, the meaning was literally 'child of both a man and a woman', presumably indicating that the individual was of noble descent in both the maternal and paternal lines (op. cit., 38). Finally, the Yucatec Maya kin term system employs a different vocabulary for male and female egos. But though different, the two systems are nearly isomorphic in structure, suggesting both double descent reckoning and matrilineages as well as patrilineages (see Eggan, 1934 and Thompson, 1978 for lists of Yucatec Maya kin terms).

Some of the basic kin terms, from the male point of view, are illustrated in Figure 2. The five terms pertinent to the succession in Figure 1 are mehen (son), han (daughter's husband or son-in-law), idzin (son's son or younger sibling), mam (daughter's son), and ca mam or ce idzin (daughter's son's son).

My work with wills and bills of sale (Thompson, 1978), written in Yucatec Maya, in the late 18th and early 19th centuries, indicates that, in the fist descending generation, the general inheritance pattern was bilineal, with a hint of patrilineality. Men left property of all kinds to both their male and female children, in equally measured shares, or biased slightly in favor of sons (Thompson, 1978: 154-165). From the male point of view (following Figure 2), a 
father (yum) usually left most of his property to his son (mehen): (28.7\% of all recipients were sons) or daughter (ixmehen) $(20.6 \%)$. There were few exclusively patrilineal or matrilineal bequests. That is, few men, with or without children of their own, left property to the children of their siblings $(1.0 \%$ were brother's children; 0.4 were sister's children).

However, in the second descending generation, there were more suggestive patterns of inheritance, involving the son's son (idzin), the daughter's son (mam) and the daughter's husband (han). If the system were patrilineal, one might expect to find a significant number of bequests to patrilineal grandchildren, a son's child (idzin), from their father's father (sucuun). But surprisingly, there were few (only $1.0 \%$ ). In contrast, the frequency of a mother's father (mam) leaving some of his property to his daughter's child (mam), a matrilineal descendant of his wife, even though he had children of his own, was relatively high $(9.0 \%)$. In a number of instances, this pattern occurred in linked fashion: A man who received property from his mother's father ( $\mathrm{mam})$ gave it, in turn, to his daughter's son $(\mathrm{mam})$. Finally, in a related pattern, a wife's father (han) often gave some of his property to his daughter's husband (han) $(3.8 \%)$, even though he had sons of his own. Other recipients included wife (atan) (11.0\%), other kin (10.6\%), fictive kin $(8.0 \%)$, cabildo officers $(1.2 \%)$, cofradias $(1.4 \%)$ and unknowns $(3.4 \%)$.

The appearance of specific patterns of inheritance connected with the daughter's son (mam) and the daughter's husband (han) suggests that there was something special about these relationships. This suggestion is underscored by the fact that both han and mam are instances of the use of an identical term for reciprocal relationships. And when these terms plus mehen and idzin are applied to the succession in Figure 1, a startling pattern emerges, as illustrated in Figure 3.

Ruler 1, Jaguar Paw (I), is succeeded by his son-in-law (han), Ruler 2, Curl Nose. Curl Nose is not a patrilineal descendant, but rather an affine, connected to Jaguar Paw (I) by marriage. If the kinship system of the 18th century was the same as the system in Classic Period Tikal, then this was not a simple son-in-law relationship. It was more complex, involving reciprocal terms and the bequest of property. The suggestion is there that the son-in-law was more than just a son-in-law.

Curl Nose is succeeded by his son (mehen), Ruler 3, a descendant 
who can be regarded as patrilineal from Curl Nose's point of view. Ruler 3, Stormy Sky, is also the daughter's son (mam) of Ruler 1. Here again, if the kin term system and the inheritance system of the 18th century are a reliable guide, then Jaguar Paw (I) had a special relationship to Stormy Sky, involving inheritance and reciprocal terms, even though he was not a patrilineal descendant. Stormy Sky was more than just a daughter's son to Jaguar Paw (I). Ruler 4, Kan boar, is the son (mehen) of Stormy Sky and the son's son (idzin) of Curl Nose. This is definitely a patrilineal succession from the point of view of both Stormy Sky and Curl Nose. But, if the 18th century inheritance patterns are a guide, from Curl Nose's point of view it is perhaps an improper succession, because it involves his son's son (idzin) rather than his daughter's son (mam).

With the succession of Ruler 5, the cycle repeats itself exactly. Ruler 5 is the son-in-law (han) of Ruler 4. Ruler 6 is the son (mehen) of Ruler 5, and the daughter's son (mam) of Ruler 4. Ruler 7 is the son (mehen) of Ruler 6, the son's son (idzin) of Ruler 5.

With the succession of Ruler 8, the cycle appears to begin again for the third time. Ruler 8 is the son-in-law (han) of Ruler 7. Ruler 9 is the son (mehen) of Ruler 8 and the daughter's son (mam) of Ruler 7. But in the next step there is a divergence from the previous pattern. Rather than pass to Ruler 9's son, the succession goes to his son-in-law $(\mathrm{han})$, and the longer cycle picks up from there for a fourth time. Significantly, this variation in pattern avoids the transmission of office to Ruler 8's son's son (idzin).

The threefold repetition of a long cycle (to son-in-law, to son, to son, and back to son-in-law), with the single appearance of a short cycle (to son-in-law, to son, and back to son-in-law), is truly startling and cannot be ignored. It demands explanation. In the following paragraphs I will consider these cycles as general patterns which underlie the observed succession. They are the key, I believe, to the relationship between descent, marriage and the succession of political power in Classic Period Tikal. Once these patterns are laid out, I will return to the actual succession in Figure 1, and show how it can be understood.

\section{The Short Cycle}

Figure 4. illustrates my interpretation of the short cycle, the more interesting of the two. It is based on the assumption, justified by 
the work of Eggan (1934), that the Maya could marry their first cross cousins, either matrilateral (FZS $=\mathrm{MBD}$ ) or patrilateral $(\mathrm{MBS}=\mathrm{FZD})$. The reader should realize that there are a number of ways to construct this diagram, given the two alternatives of the marriage rule. I have chosen the pattern which appears in Figure 4 for two reasons. First, it demonstrates a regular pattern in the marriage rule over several generations. And second, it insures that the referents of the terms mehen, han, and mam are successors to the rulers who would be applying these terms.

TABLE 1

\section{MATRILINEAL AND PATRILINEAL AFFILIATION OF RULERS IN ORDER OF SUCCESSION AS ILLUSTRATED IN FIGURE 4}

\begin{tabular}{crrrr}
\hline \multicolumn{2}{c}{ Matrilines } & \multicolumn{2}{c}{ Patrilines } \\
$A$ & $B$ & $X$ & $Y$ \\
\hline & 1 & 1 & \\
3 & 2 & & 3 \\
4 & & 4 & \\
& 5 & 5 & 6 \\
7 & 6 & & 7 \\
8 & & & \\
& & 9 & 9 & 10 \\
11 & 10 & & & 11 \\
12 & & & & \\
\hline
\end{tabular}

In the short cycle, the seat of power passes, from the male point of view, to son-in-law (han), to son (mehen), to son-in-law (han), to son (mehen), and so on. This can be achieved only when the system alternates each generation between matrilateral and patrilateral marriage, as shown in Figure 4. Assuming that both patrilineal and matrilineal descent are traced, then control of the ruling kin position, the seat of power, alternates between two matrilines every two generations and between two patrilines every two generations, though the generation of alternation overlaps the other by one year in each case (see Table 1). Furthermore, the link between rulers, the rule of succession, is alternately matrilineal and patrilineal. When the succession passes from a ruler to his daughter's son ' (han), 
the new ruler is also his sister's son, belonging to his matriline, but not his patriline. When the successsion passes from a ruler to his son (mehen), the new ruler belongs to his patriline, but not his matriline. As a result, half of all successions are patrilineal and half are matrilineal. Looking at the next generation, it is clear from Figure 4 that each ruler is the daughter's son ( $\mathrm{mam}$ ) of the ruler in the second ascending generation. In fact, every other ruler in this system is linked by the daughter's son/mother's father ( $\mathrm{mam} /$ mam) relationship, in the same manner that some property was transmitted from mam to $\mathrm{mam}$ to $\mathrm{mam}$ in the 18th century.

The patterns just described are the result of the fact that, in the short cycle, there are four classes of rulers - those of matriline A and patriline $\mathrm{Y}$, those of matriline $\mathrm{A}$ and patriline $\mathrm{X}$, those of matriline $\mathrm{B}$ and patriline $\mathrm{Y}$, and those matriline $\mathrm{B}$ and patriline $\mathrm{X}$ alternating the seat of power in a four generation cycle. This system, composed of two matrilines and two patrilines, is strongly suggestive of the 'four section' or Kariera kinship system (see Fox 1971: 175-195). Indeed, all that is needed to produce a structural model of the Kariera system is to assume that the system is closed - that there are only two matrilines and two patrilines, as depicted in Figure 5.

For the system to be truly Kariera each of the classes would have to be a named section. As far as I am aware, there is no evidence, to date, of named sections among the Maya. Thus, for now, the system might best be described as 'Kariera-like'. Nevertheless, named sections may have existed. The fact that a double descent system, with both patriline and matriline exogamy, would produce four marriage classes could not go unnoticed by the Maya, given their preoccupation with the number 'four'. Perhaps the system of four year-bearers was originally associated with named sections, rather than residential wards. In such a system, each section might include a number of named matrilines and patrilines.

In one way or another, a number of people have suggested that the Mayan kinship system was Kariera-like. In a detailed analysis of contemporary Lacandon kinship, Michael J. Rees (1977) has found a comparable pattern. By concluding that the Yucatec Maya had exogamus patrilineages and matrilineages, and practiced direct brother-sister exchange, Floyd Lounsbury (in Coe, 1965: 104) says the same thing. Finally, Munro Edmonson (personal communication) believes that, though the Yucatec kin term system is probably a 
mixture of more than one type, the underlying pattern was Karieralike, with the question of named sections open to discovery.

The Yucatec kin term system lends support to the view that the Maya kinship system was Kariera. A complete kin term analysis would be too complex and time-consuming to undertake here (see Thompson, 1978: 62-110). However, the point can be illustrated, at least, with the following observations. First, reciprocal relationships of alternate generations, from the male point of view, have identical terms, if they are connected through female links ( $\mathrm{mam}$ ), and terms expressive of sibling identity, if they are connected through a male link (sucuun and idzin). This pairing of alternate generations is typical of Kariera systems, in which the same two sections, in alternate generations, exchange sisters and brothers (Fox, 1967: 188). As a result, for each male, there are two kinds of male relatives in the second ascending generations: Those who are in the same class as Ego - same patriline and same matriline (sucuun and idzin) -and those who are in the opposite class from Ego- different patriline and different matriline $(\mathrm{mam})$. In other words, there are those to whom Ego's class gives wives and from whom Ego's class receives wives ( $\mathrm{mam})$, and those who belong to Ego's own class (sucuun and idzin). This interpretation is corroborated by the Diccionario de Motul which translates mamil as 'parentesco de afinidad' ('kinship by marriage') ('Ciudad Real, 1929: 601-602). It goes on to define two verb forms, maminah and mamintah, as "emparentar o contraer parentesco por casamiento, in mamintah batab, emparenté con el cacique, que se casó mi hijo con su nieta, hija de hija' ('to relate or contract kinship by marriage, in mamintah $b a t a b$, I related myself with the cacique, since my son married his granddaughter, daughter of a daughter'). Likewise, the Arte de el Idioma Maya (Beltrán, 1746: 175) gives 'afinidad' ('affinity') as a translation for mamih, mamilah and mamilthan.

Second, the Kariera model, as presented in Figure 5, indicates that a man's son's son's son is also his daughter's daughter's son. This suggests that the same term might be applied to both positions. In fact, this is probably true. As Figure 2 illustrates, the children of a man's daughter's children are called caa mam or caa idzin. And, his son's children's children are called caa idzin. Thus, though different terms may be used, there is one common term. 


\section{The Long Cycle}

In the long cycle succession passes to son (mehen), to son (mehen), to son-in-law (han), and so on. Figure 6 presents one possible illustration of this pattern of succession, based on the same rules followed in the short cycle - that both patrilateral and matrilateral marriage be allowed, that the various successors be son's son (idzin), daughter's son (mam), son-in-law (han) and son (mehen), when possible, and that the resulting figure exhibit a regular and recurring marriage patern. To this list I have added one more criterion. It is ordered to show that two matrilines could be defining factors in this system of succession.

In the long cycle, as depicted in Figure 6, marriage alternates each generation in the following pattern:

$\begin{array}{lll}\text { FZD } & \text { MBS } & \text { patrilateral } \\ \text { FZD } & \text { MBS } & \text { patrilateral } \\ \text { FZS } & \text { MBD } & \text { matrilateral } \\ \text { FZD } & \text { MBS } & \text { patrilateral } \\ \text { FZD } & \text { MBS } & \text { patrilateral } \\ \text { FZS } & \text { MBD } & \text { matrilateral } \\ \text { FZD } & \text { MBS } & \text { patrilateral }\end{array}$

etc.

\begin{tabular}{|c|c|c|c|c|c|c|}
\hline \multicolumn{2}{|c|}{ Matrilines } & \multicolumn{5}{|c|}{ Patrilines } \\
\hline$A$ & $B$ & $X$ & $Y$ & $Z$ & $A$ & $B$ \\
\hline & 1 & 1 & & & & \\
\hline 3 & 2 & & $\begin{array}{l}2 \\
3\end{array}$ & & & \\
\hline & 4 & & 4 & & & \\
\hline 6 & 5 & & & $\begin{array}{l}5 \\
6\end{array}$ & & \\
\hline & 7 & & & $\begin{array}{l}0 \\
7\end{array}$ & & \\
\hline & 8 & & & & 8 & \\
\hline 9 & & & & & 9 & \\
\hline & 10 & & & & 10 & \\
\hline 12 & 11 & & & & & $\begin{array}{l}11 \\
12\end{array}$ \\
\hline
\end{tabular}


As required, this pattern produces the necessary successsion to son (mehen), to son (mehen), to son-in-law (han), etc. But most important is the result that all the rulers in Figure 6 belong to one of two matrilines - matrilines $A$ and $B$. All of the rulers are either the husbands or the brothers of the women in matrilines $A$ and $B$. Since matriline $B$ controls two of every three successions (i.e., when the rulers are brothers rather than husbands of matriline B), rather than two of every four, it might be said that it is "defining" the succession or that it is a "ruling" matriline. However, the symmetry of the short cycle suggests that matriline B should be regarded as a usurper of matriline A's rightful control of one out of every four generations.

An important feature of the long cycle is that it rotates matrilines and patrilines through the succession at different frequencies from the short cycle. As Table 2 makes clear, matrilineal control of the seat of power alternates between matrilines $\mathrm{A}$ and $\mathrm{B}$ - one term for $\mathrm{A}$, two terms for $\mathrm{B}$, one term for $\mathrm{A}$, etc. But, patrilineal control of the office passes from patriline to patriline, each ruling for three generations, with none of the patrilines necessarily reappearing in the succession, though in practice control could rotate in a closed system between two or more patrilines.

If the long cycle is compared to the closed short cycle composed of two matrilines and two patrilines, as in Figure 5, the contradictions of the short and long cycles become clear. Succession in the short cycle is alternately matrilineal and patrilineal. In the long cycle, each time a man succeeds both his father and his father's father as ruler, he usurps, according to the rules of the short cycle, the rightful succession of his wife's brother, his mother's brother's son, his first cross cousin. However, the fact that this occurs is not suprising or inexplicable. Rules are oiten broken, and this is a likely one to break. It reflects the desire of a man to see his son, rather than his sister's son, succeed him in office. And, since the system is based on double descent, there is some validity to the claim of each aspirant, whether the moment calls for a patrilineal descendant or a matrilineal descendant. The crucial fact about this particular kind of breach is that it violates a short-term rule of succession without breaking a long-term rule - namely, that the seat of power is defined by two matrilines. In fact, this criterion can be met, and a single patriline control the succession indefinitely, as long as all the rulers marry only their patrilateral cross cousins (see Figure 7). Variations such as these must be regarded as representing political maneuvering. When the possibility of polygyny, as well as the proba- 
bility that a ruler will have a number of sons and daughters, are added to the system, there is more than enough latitude for political maneuvering and intrigue.

Before returning to the succession presented in Figure 1, the following summary of the preceeding sections is in order. It is my belief that the Maya of Tikal traced descent in both the male and female lines and that they recognized both matrilineages and patrilineages. Patrilineages were the groups which competed for control of political office. Matrilineages, whatever their other functions, regulated marriage (Lounsbury in Coe, 1965: 104). And they were probably organized at higher level of integration into matriclans or matrimoieties which defined and regulated political succession by regulating marriage. Furthermore, the basic model for succession was probably the short cycle, in which the seat of power passed alternately to patrilineal and matrilineal heirs, producing a four generation cycle in which each ruler belonged to one of four Karieralike classes. Deviation from this pattern was common, but when it occurred, it was the competing patrilineages which deviated. The underlying continuity of succession defined by two matrilines (matrimoieties) was maintained.

\section{The Actual Succession (Figure 1)}

The actual succession of Figure 1 varies greatly from the model of the short cycle. The Middle Classic Period was a time of political unrest and strife (Coggins, 1979) and the succession reflects it. Yet, the underlying continuity of the succession is maintained - the seat of power is defined and shared by two matrilines- and, as already indicated, all of the deviations from the short cycle follow a regular and understandable pattern - the long cycle.

Figure 8 presents an interpretation of the descent and marriage sequence which produced the gencalogy of Figure 1 . To explain it, I will begin with Kan Boar, Ruler 4. According to the model of the short cycle, his succession breaks the rule that Stormy Sky should be succeeded by a matrilineal heir - his sister's son and daughter's husband. Thus, Kan Boar, a patrilineal heir of Stormy Sky, usurped the rightful succession of his cross cousin. And, in fact, there seems to be archaeological evidence of a conflict between Kan Boar and a rival pretender (Coggins, 1979: 8-9), just as this model predicts.

From Kan Boar succession passes to Ruler 5, the husband of his daughter, the Woman of Tikal. Haviland stresses the fact that the 
Woman of Tikal receives a great deal of attention in the stelae and tomb inscriptions (Coggins, 1975: 219-220, 256, 312, 381; Haviland, 1977: 63), arguing that she is a woman substituting for a male link in a patriline from Kan Boar to Jaguar Paw (II), Ruler 6. I believe, on the contrary, that she was given a great deal of attention because she was a member of one of the two ruling matrilineages of Tikal, but married to a genealogical "outsider" - a man who was not a member of the other ruling matrilineage. There are two kinds of daughter's husbands. One is also sister's son, and belongs to ego's own matrilineage. The other is wife's brother's son, and belongs to another matrilineage entirely. Succession to the former insures that the new ruler will belong to one of the ruling matrilineages and be married to a woman belonging to the other. Succession to the latter results in a new ruler who is of another matrilineage altogether and whose only connection to the ruling matrilineages is through his wife. I have constructed the marriage type in Figure 8 to conform to the latter pattern. As a result, ruler 5 can legitimately claim the seat of power only by virtue of his marriage to the Woman of Tikal - hence the emphasis on her in the archaeological evidence.

A later ruler (whom Haviland, following Coggins, suggests is Ruler 6, Jaguar Paw (II)) traces his ancestry back through the Woman of Tikal to Stormy Sky. I believe that this ruler was, in fact, Ruler 6, the son of the Woman of Tikal. He was tracing his ancestry back to the last preceeding ruler, who was, like himself, a male member of matriline B and married to matriline A. And, as will be apparent, there is reason to believe that Stormy Sky was considered the "founder" of the succession defined by matrilines A and B. Thus, Jaguar Paw (II) alluding to his relationship, through the Woman of Tikal, to the last truly legitimate ruler, and founder of the succession, Stormy Sky. In a sense, he stated the cycle over again.

Four rulers beginning with Ruler 6, and ending with Ruler 9, follow the Kariera pattern exactly. Ruler 6 belongs to matriline $B$ and patriline X. Ruler 7 belongs to matriline A and patriline X. Ruler 8 belongs to matriline A and patriline Y. And, Ruler 9 belongs to matriline B and patriline Y. I have drawn their marriages so as to produce this pattern, but still conform to the succession presented in Table 1. The Kariera-like system would continue if Ruler 9 were depicted as marrying patrilaterally. I have chosen not to do so for reasons which will become clear shortly.

Ruler 8 is a particularly crucial link. If regarded as a genealogical outsider, belonging to matriline C like Ruler 5 , then his wife should 
be an important figure in the archaeological record, just as the Woman of Tikal was an important figure. But, there is no known mention of her (Coggins, 1975: 257, 341, 359, 370, 382; Haviland, 1977: 63), and this fact has led me to regard Ruler 8 as a member of matriline A married to matriline B, despite the fact that he is portrayed as a geographical outsider, a "man from the southeast", by Coggins and Haviland (Haviland, 1977: 63). Figure 9 is a diagram of the results of depicting Ruler 8 as an "outsider", a member of matriline C. I will consider it later.

Returning to Figure 8, the succession from Ruler 9 to Ruler 10 was to a son-in-law who was also a patrilineal descendant of Ruler 7. This is the only case in the Coggins diagram where the true kin links of both spouses are known. The fact that Figure 8 (and 9 and 10) can accommodate this information and still meet the other demands of the succession, supports the assumption that the Maya practiced first cross cousin marriage both patrilaterally and matrilaterally. There is a problem, however. There are at least two alternative ways of fulfilling the succession from Ruler 9 to Ruler 10. Ruler 10 can be depicted as the wife's brother's son of Ruler 9, as in Figure 8. Or, he can be depicted as the sister's son of Ruler 9, as in Figure 10. These are the same alternatives present in the cases of Rulers 5 and 8 . And, each has important consequences for the underlying matrilineally defined succession. If Ruler 10 is depicted as the sister's son of Ruler 9, then it is possible to show that matrilines $\mathrm{A}$ and $\mathrm{B}$ remain as the ruling matrilines, as in Figure 10. On the other hand, if Ruler 10 is regarded as the wife's brother's son of Ruler 9, then matrilines $A$ and $B$ cease to be the ruling matrilines, and the potential for establishing a new pair of ruling matrilines is created, as shown in Figure 8. I believe that this is the case, for a number of reasons.

First, the wife of Ruler 10 received almost as much fanfare in the monuments as the Woman of Tikal (Coggins, 1975: 455-456, 549-551, 554; Haviland, 1977: 64). In Figure 10 there is no evident reason why this woman should receive attention. However, if her structural position is as depicted in Figure 8, then there is good cause to celebrate her in the inscriptions: She is the founding female of a new pair of ruling matrilines in Tikal.

A second and more momentous bit of evidence in support of Figure 8, rather thant Figure 10, is the fact that the succession of Ruler 10 occurred on the 13 katun anniversary of the succession of Stormy Sky (Coggins, 1975: 9, 379-380, 390, 391, 444, 446). A 
260 tun cycle was ending, and another beginning. It is logical to assume that power changed hands, or rather matrilines, with the closing of one cycle and the opening of another. This implies that the matrilines of Ruler 10 and his wife were to be the ruling matrilines for the next 260 tuns or 13 katuns.

The fact that the succession of Ruler 10 was on the 13 katun anniversary of the succession of Stormy Sky suggests that Stormy Sky and his wife founded the matrilines A and B which ruled for 13 katuns. In fact, the monument to the succession of Ruler 10 makes many references to Stormy Sky and Curl Nose, his father (Coggins, 1975: 401-402, 444-445, 450, 452, 548; Haviland, 1977: $64)$. And Curl Nose is known to have been an outsider, probably from Kaminaljuyu (Haviland, 1977: 63). With these points in mind I have drawn Figure 8 to show a transition of power from matrilines C and D (assuming that Jaguar Paw [I] was the wife's brother's son of the previous ruler) to matrilines $\mathrm{A}$ and $\mathrm{B}$ in the succession from Jaguar Paw (I) to Curl Nose. The result suggests that the wife of Curl Nose should be celebrated in the stelae inscriptions, as co-founder of a new pair of ruling matrilineages. She is not (Haviland, 1977: 63). Nevertheless, I think that the interpretation of Figure 8 is justified on the strentgh of previous arguments.

The formation of a new pair of ruling matrilines was made possible by the marriage of Curl Nose to a woman of matriline B, who was also the daughter of Jaguar Paw (I) and, thus, partially legitimized Curl Nose's succession. But, the new ruling matrilines were not confirmed in their role until the patrilateral marriage of Stormy Sky. Had he married matrilaterally, to a woman of matriline C, then matriline $\mathrm{G}$ would have returned to a ruling position. This is precisely what happens with the son of the Woman of Tikal, and for this reason matrilines A and B remain in power at that point. Thus, it is Stormy Sky who confirms the new ruling matrilineages and is regarded as the founder of the succession. Hence, a transition from one pair of ruling matrilines to another pair takes two steps. This suggests, of course, that Ruler 11, and not Ruler 10, was eventually to be regarded as the founder of a new pair of ruling matrilineages.

The hypothesis that Stormy Sky's succession to the ruling position marked the beginning of a 260 tun cycle, is corroborated, to a degree, by Colonial Yucatec Maya sources. Stormy Sky was inaugurated on the half cycle date $8 \cdot 19.10 .0 .0$, between 8 Ahau and 6 Ahau, and reigned for the opening of 6 Ahau in 9.0.0.0.0. Ruler A ascended 
in 9.12.9.17.16, just four days short of the 13 katun anniversary of Stormy Sky's inauguration. Again, this was on the date of the half cycle, between 8 Ahau and 6 Ahau, and Ruler A reigned for the opening of 6 Ahau in 9.13.0.0.0. Counting the 13 katun cycle from 6 Ahau to 8 Ahau was typical of the Xiu lineage in the Colonial Period (Munro Edmonson, personal communication). A rival count considered the cycle to begin and end at the juncture of katuns 13 Ahau and 11 Ahau. Interestingly, this is approximately the point (9.3.10.0.0) at which Kan Boar, whose authority was disputed, was still in office. The fact that these rival views 'fit' the Tikal data, as I have interpreted it, suggests that the katun count itself and the complete cycle of 13 katuns, as well as the dispute over starting points, run deep in Mayan history. Perhaps the inauguration of Stormy Sky represented the first time an 8-6 count was initiated. The dispute in the reign of Kan Boar would represent an attempt by the 'old guard' to re-instate themselves on the basis of an older 13-11 count. Coggins has suggested a similar interpretation, but based on slightly different evidence (1979: 22-23).

Finally, returning to the diagrams, Figure 9 presents a variation on the pattern presented in Figure 8. It depicts Ruler 8 as a wife's brother's son, rather than a sister's son, and emphasizes his possible 'otuside' genealogical origins. This has two effects. First, it breaks the regular cycle of succession for Rulers 6 through 9. And second, it slightly alters the meaning of the transmission of power from Ruler 9 to Ruler 10. Rather than marking a transition from one pair of ruling matrilines to another pair, Figure 9 suggests that one matriline is dropped and one is added, with one continuing to serve as a ruling matriline. Matriline $\mathrm{B}$ is dropped. Matriline $\mathrm{Z}$ is added. And matriline $A$ remains in a ruling position, alternating with matriline $\mathrm{Z}$. Thus, rather than a pair of matriline entering and leaving a ruling position every 13 katuns, there may have been an overlap whereby one matriline ruled for two 13 katun periods, but with a different 'partner' matriline in each 13 katun period.

\section{Conclusion}

Figures 8, 9 and 10 do not rigidly follow the alternating patrilinealmatrilineal pattern of succession which I have associated with a Kariera-like kinship system. This is so because of the long cycle deviation, as expected, and also because of 'outsider' descent lines entering the line of succession. In Figure 9, Ruler 8, of patriline W 
and matriline $\mathrm{C}$, is an outsider. In all three figures Ruler 5, depicted as a member of patriline $\mathrm{X}$ and matriline $\mathrm{C}$, could just as well have been shown as a member of another patriline, and a complete outsider both matrilineally and patrilineally. But, as the three figures indicate, the proper cross cousin marriage in the next generation easily integrates a newcomer into the matrilineally defined succession. In other words, outsiders could marry into the line of succession as long as they were neither matrilineally nor patrilineally related to their wives, i.e. as long as they had different matronymics and patronymics. And, in so indicating, the diagrams illustrate the probability that political succession was defined by two underlying matrilines.

Given double descent and bilateral cross cousin marriage, one way for an elite to monopolize control of political office is to attempt to alternate succession first to a patrilineal heir, then to a matrilineal one, and so on in a four generation cycle in which each ruler belongs to one of four Kariera-like classes. Real world political pressures would distort this pattern in the manner shown in Figures 8,9 and 10 , through retention of control by 'insider' patrilines and intrusion by 'outsider' patrilines. I find Figure 8 most satisfying because it best explains the archeological data, as I see it, and allows one alternating or Kariera-like sequence. Figure 9 does not allow such a pattern, and Figure 10, while it does, fails to account for the archaeological evidence.

\section{Acknowledgement}

I am indebted to Victoria R. Bricker for suggesting that I evalute Haviland's article in light of my own research and for her encouragement, suggestions and criticisms at every stage in the development of this paper. Other readers include Munro Edmonson, E. Wyllys Andrews IV and Marcia Jordan Thompson. To them 1 express my gratitude for their advice and comments. Also, I would like to thank Annette Harper for turning chaotic scribblings into readable diagrams.

This paper is based, in part, on work carried out with funds provided by the American Philosophical Society (Phillips Fund), The Shell Oil Company and The Betty Jordan Foundation. 


\title{
REFERENCES
}

\author{
Beltrán de Santa Rosa, Fray Pedro \\ 1746 Arte de el Idioma Maya. México. \\ (Giudad Real, Fray Antonio de) \\ 1929 Diccionario de Motul. Juan Martínez Hernández, Ed. Mérida, \\ Yucatán: Talleres de la Compañía Tipográfica Yucateca, S. A. \\ Coe, Michael D. \\ 1965 "A Model of Ancient Community Structure in the Maya Low- \\ lands". Southwestern Journal of Anthropology 21: 97-114. \\ Coggins, Clemency Chase \\ 1975 Painting and Drawing Styles at Tikal: An Historical and Ico- \\ nographic Reconstruction. Ph. D. dissertation, Harvard Uni- \\ versity, University Microfilms, Ann Arbor. \\ 1979 "A New Order and the Role of the Calendar: Some Charac- \\ teristics of the Middle Classic Period at Tikal". Maya Archaeo- \\ $\log y$ and Ethnohistory, Ed. by N. Hammond and G. R. Willey, \\ EGGAN, Fred \\ p. 38-50. University of Texas Press, Austin. \\ 1934 "The Maya Kinship System and Cross-Cousin Marriage". Ame- \\ rican Anthropologist 36: 188-202. \\ Fox, RobIN \\ 1971 Kinship and Marriage: An Anthropological Perspective. Har- \\ mondsworph, Eng.: Penguin (First published in 1967).

\section{Havmand, Wriliam A.} \\ 1977 "Dynastic Genealogies frrom Tikal, Guatemala: Implications for \\ Descent and Political Organization". American Antiquity 42: \\ 61-67.
}

ReEs, Michael J.

1977 Mathematical Models of Lacandon Kinship. Ph. D. dissertation,

\section{ROYS, RALPH} Tulane University, University Microfilms, Ann Arbor.

1940 "Personal Names of the Maya of Yucatan". Contributions to American Anthropology and History 31: 31-48 (Publications 523). Washington, D. G.: Carnegie Inst. Wash.

Thompson, Philip C.

1978 Tekanto in the Eighteenth Century. Ph. D. dissertation, Tulane University, University Microfilms, Ann Arbor.

Vienna DictionaRy

1972 Bocabulario de la Lengua Maya. Kopenhagen: Einleitung Ernst

Mengin Akademische Druck-u. Verlagsanstalt Graz-Austria. 


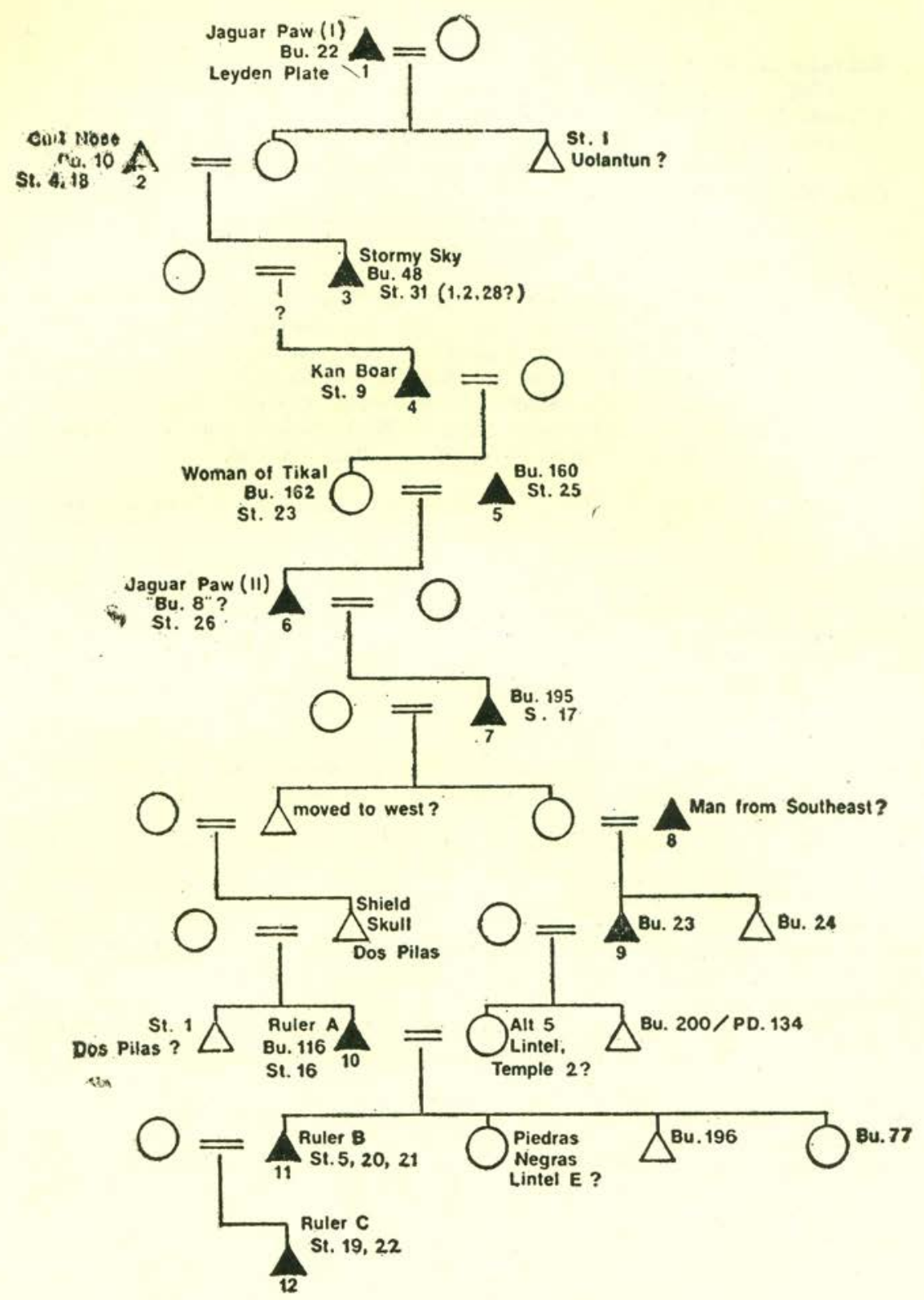

Figure 1. Proposed dynastic succession at Tikal (Source: Coggins, 1975: Table 4.) 


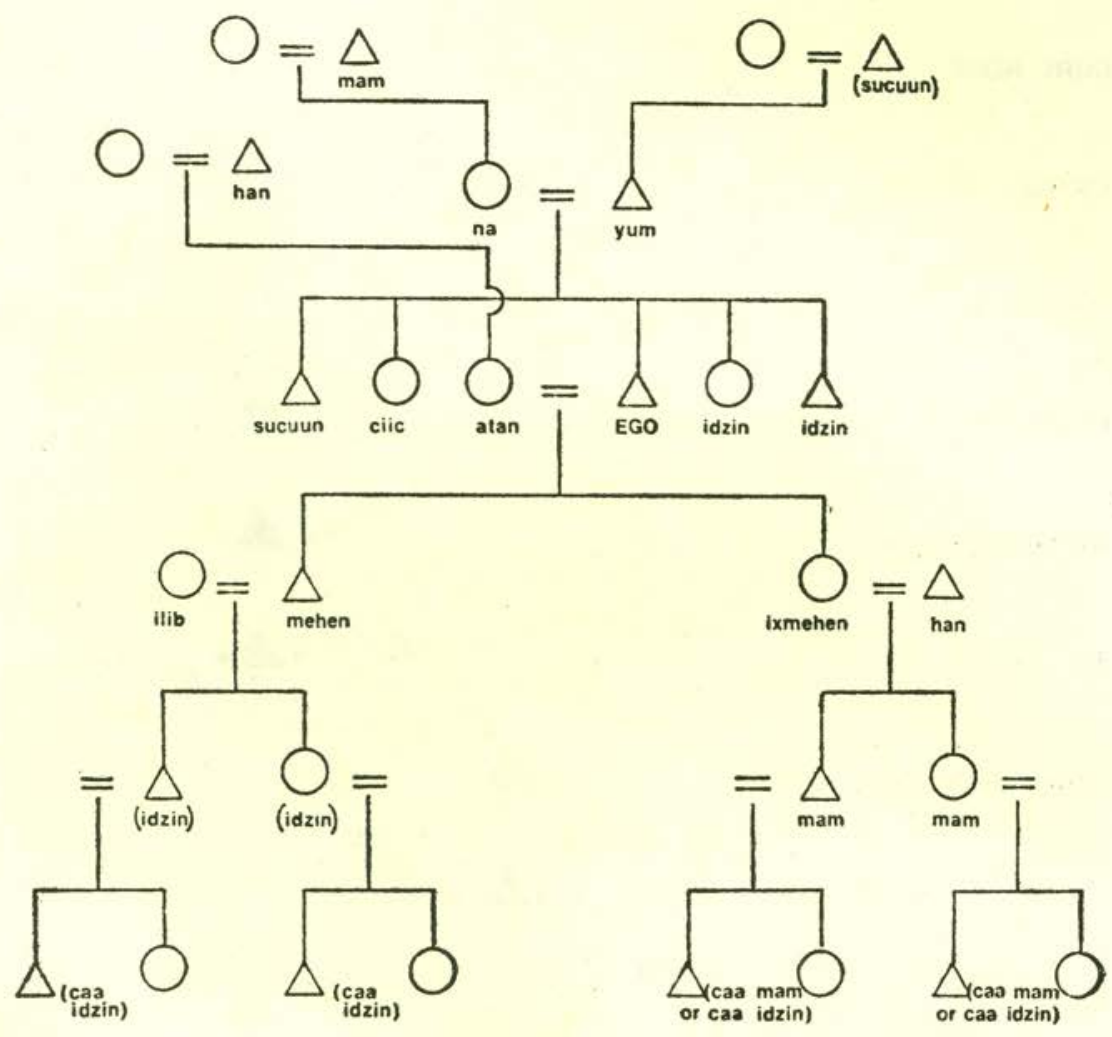

Figure 2. Various Colonial Yucatec Maya kin terms, male-speaking. Terms not in parentheses commonly appear in documents from the 18th Century (Thompson 1978). Terms in parentheses can be found in the Diccionario de Motul (167, $171,264,461)$ and the Vienna Dictionary $(27 \mathbf{r})$. 


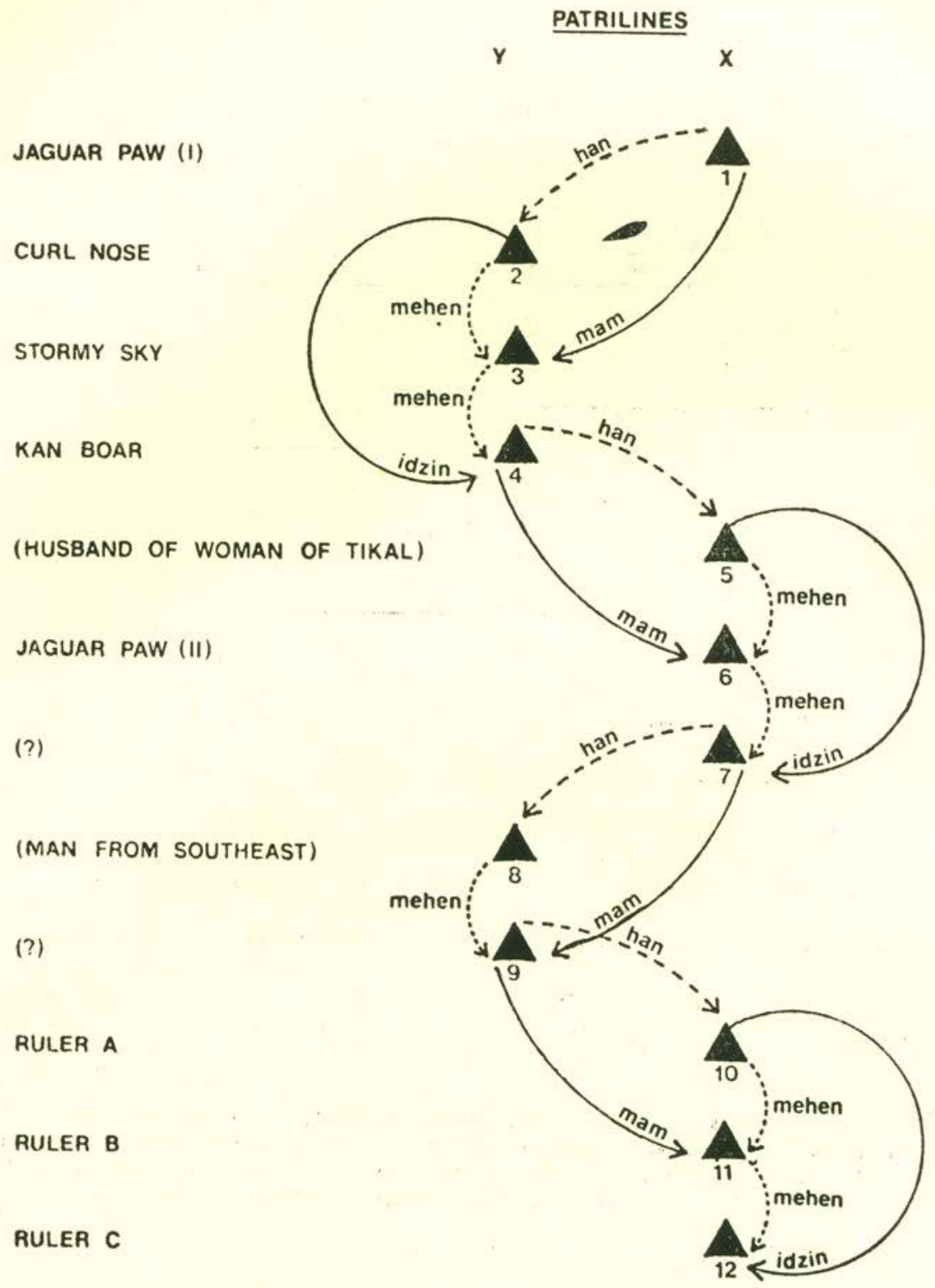

Figure 3. Application of Colonial Yucatec Maya kin terms to the proposed dynastic succession at Tikal. 


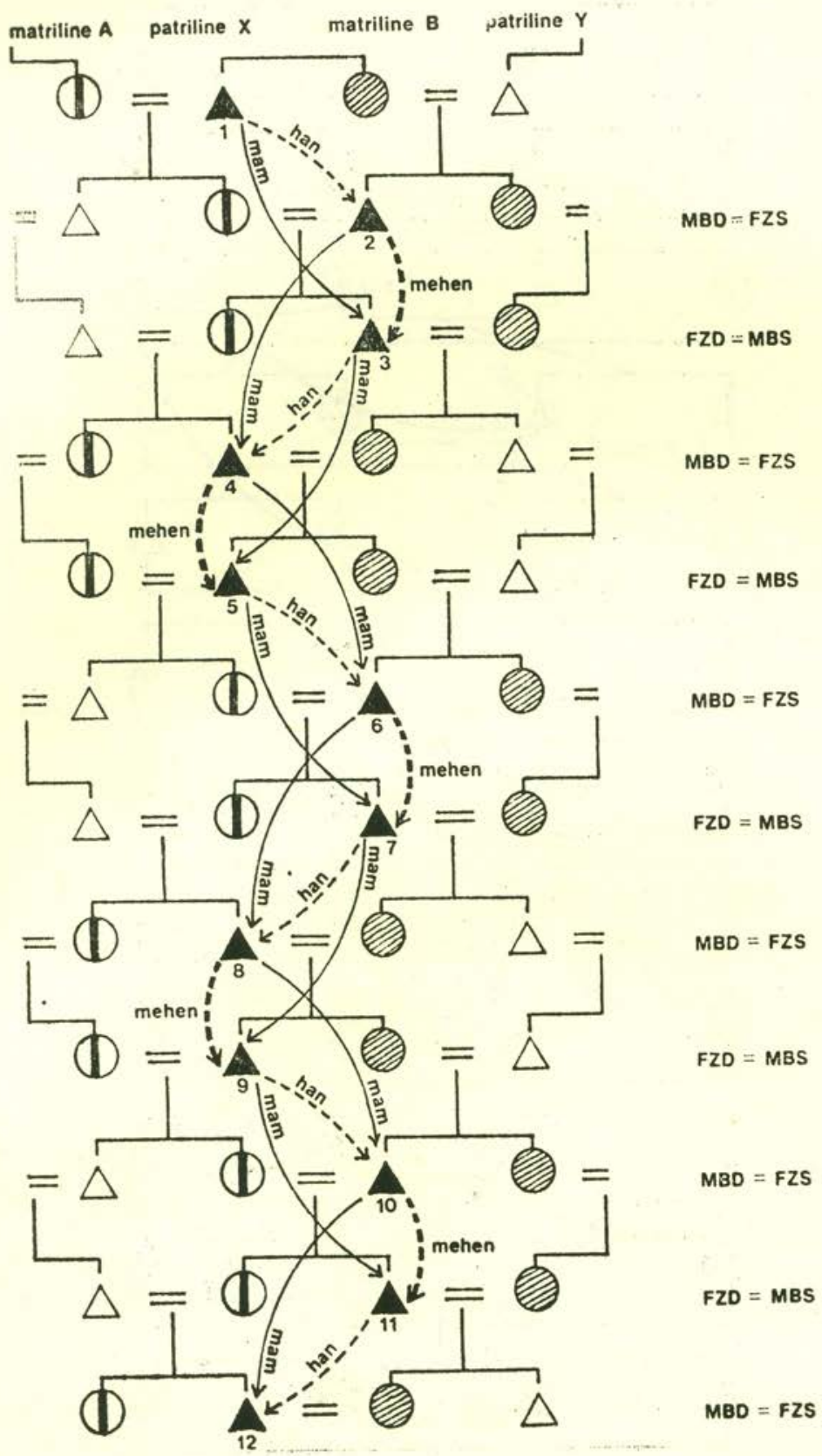

Figure 4. The 'Short Cycle' in which succession passes alternately to son-in-law, to son, to son-in-law, to son, etc. 


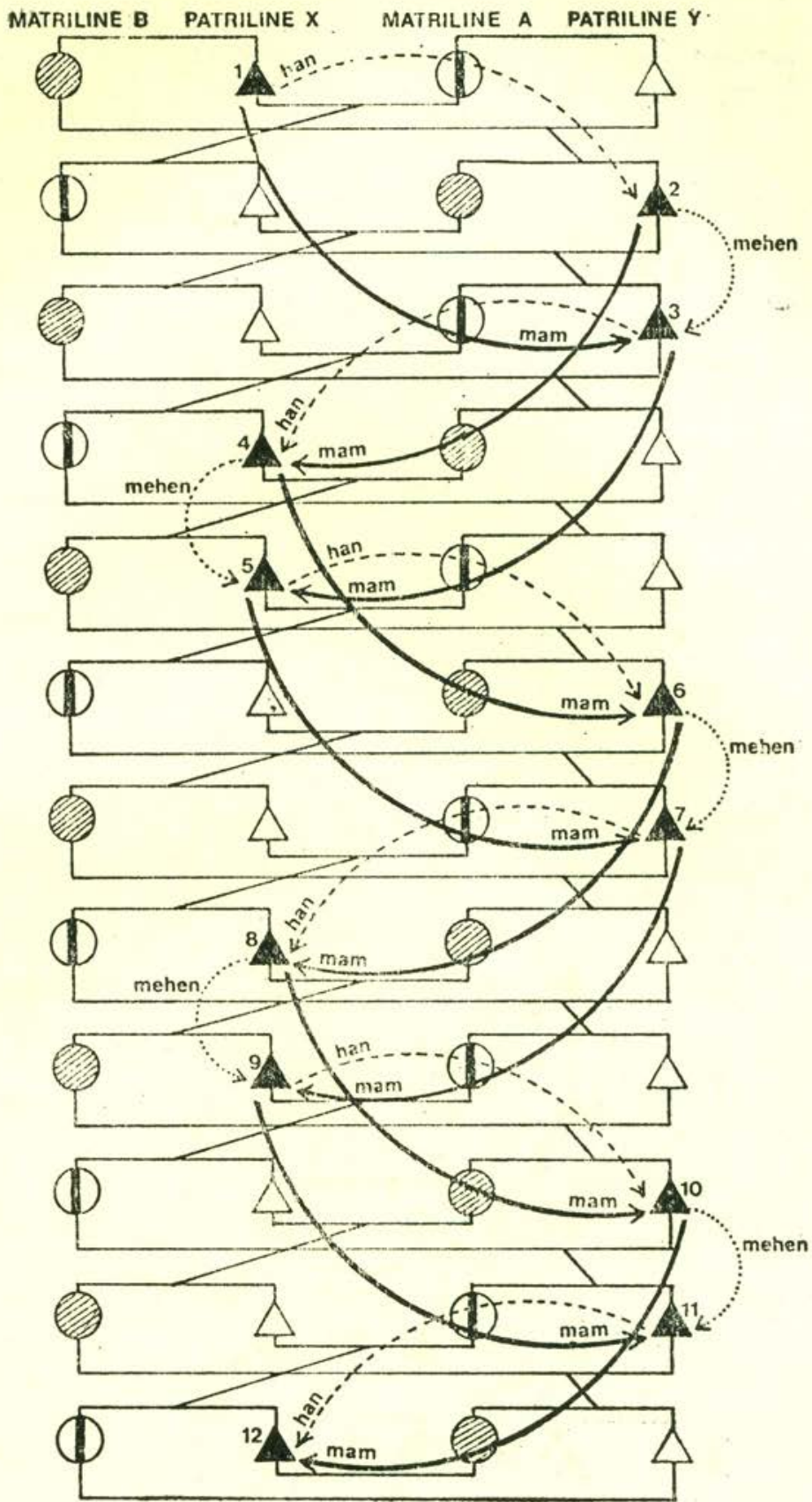

Figure 5. The 'Short Cycle' as a closed system with only two matrilines and two patrilines. 


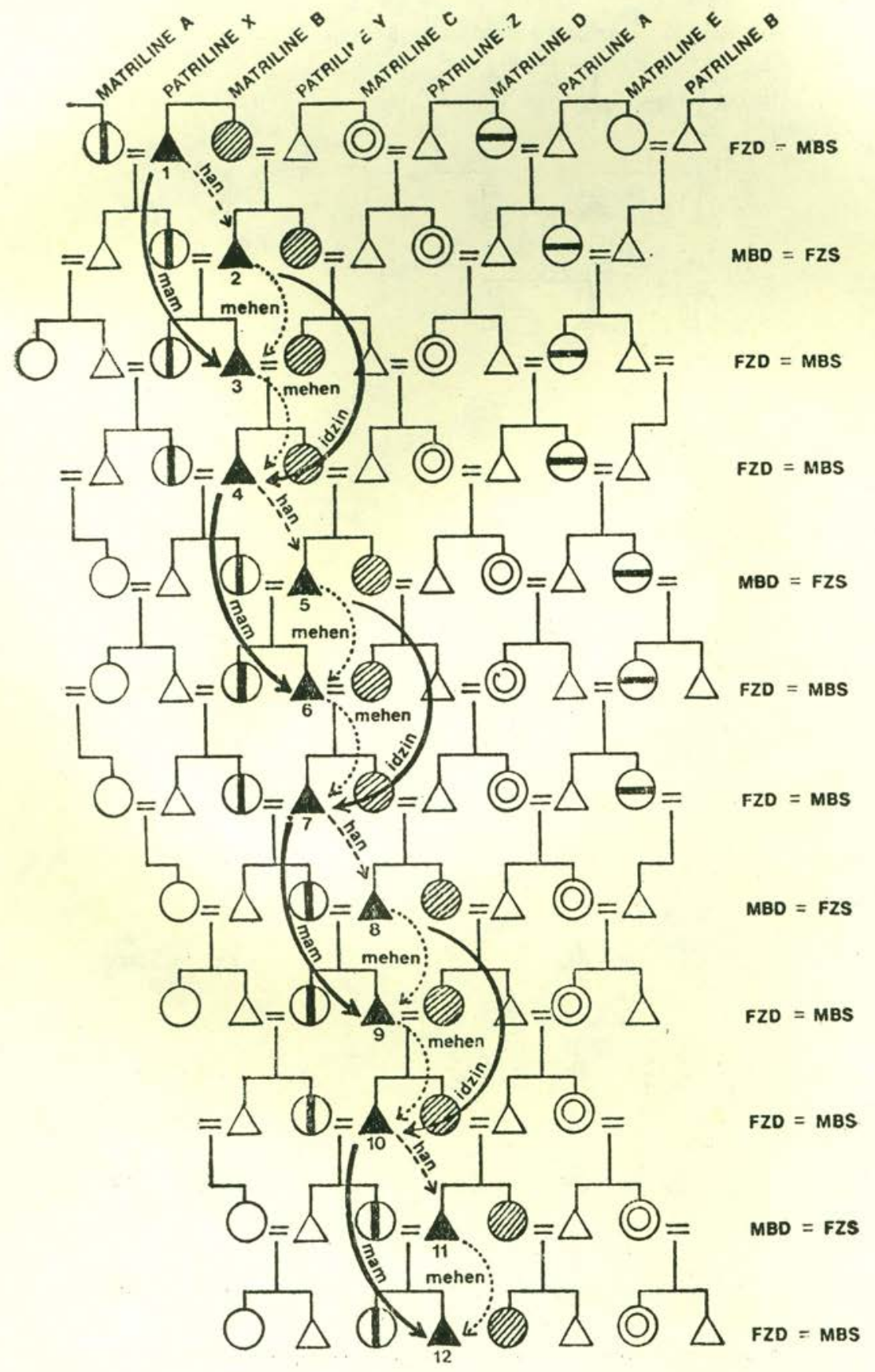

Figure 6. The 'Long Cycle' in which succession passes to son-in-law, to son, to son, to son-in-law, to son, to son, and so on. 
IATRILINE A PATRILINE X MATRILINE B

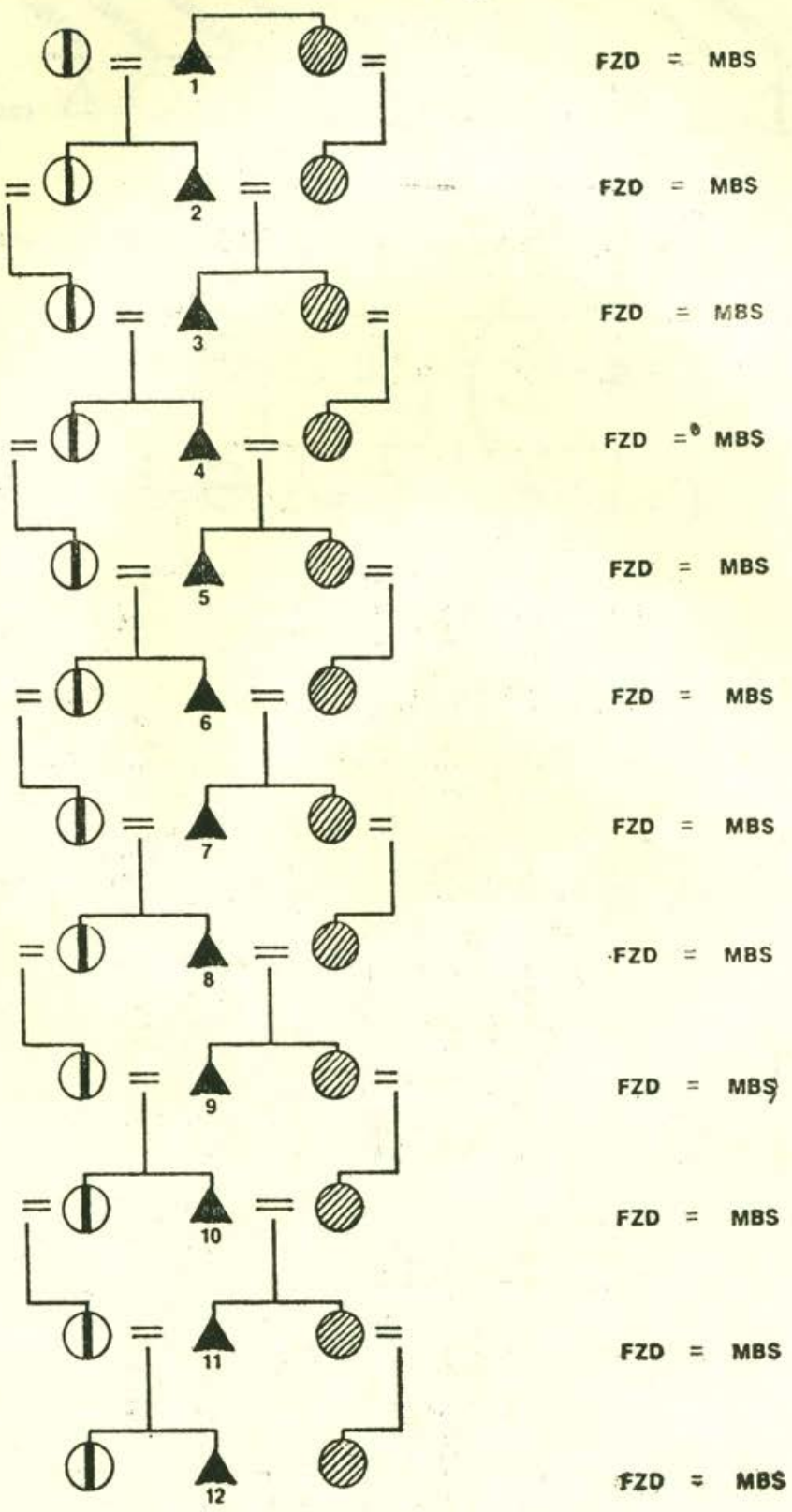

Figure 7. A succession defined by two matrilines. A and B, but controlled by only one patriline, $\mathbf{X}$, as the result of consistent patrilateral cross cousin marriage. 


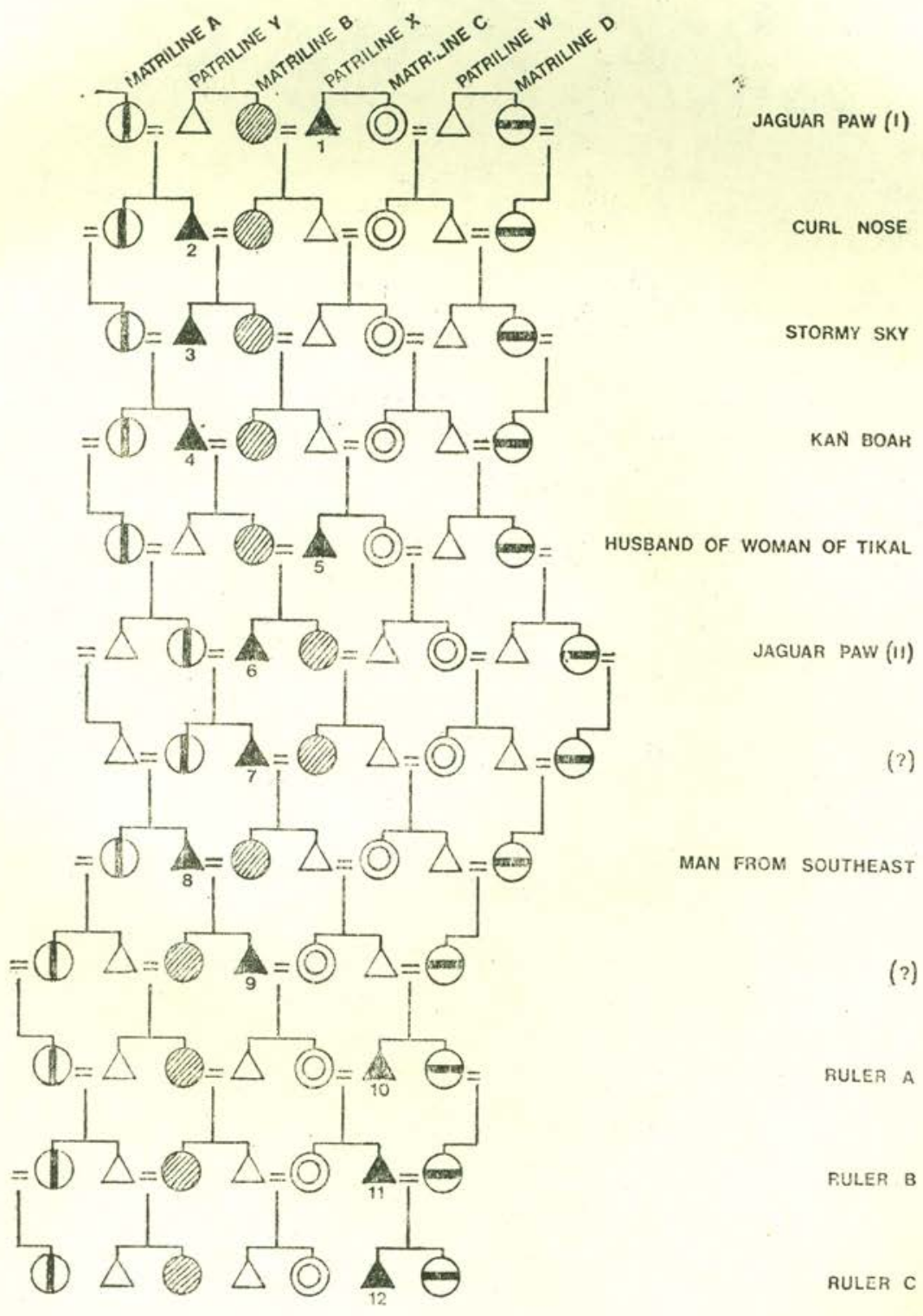

Figure 8. Interpretation of the dynastic succession at Tikal which assumes that Ruler 5 is an outsider, that Ruler 8 is not, and that the inauguration of Ruler 10 involves the initiation of a new 260 tun cycle in which two different matrilines replace the two matrilines of the previous cycle. 


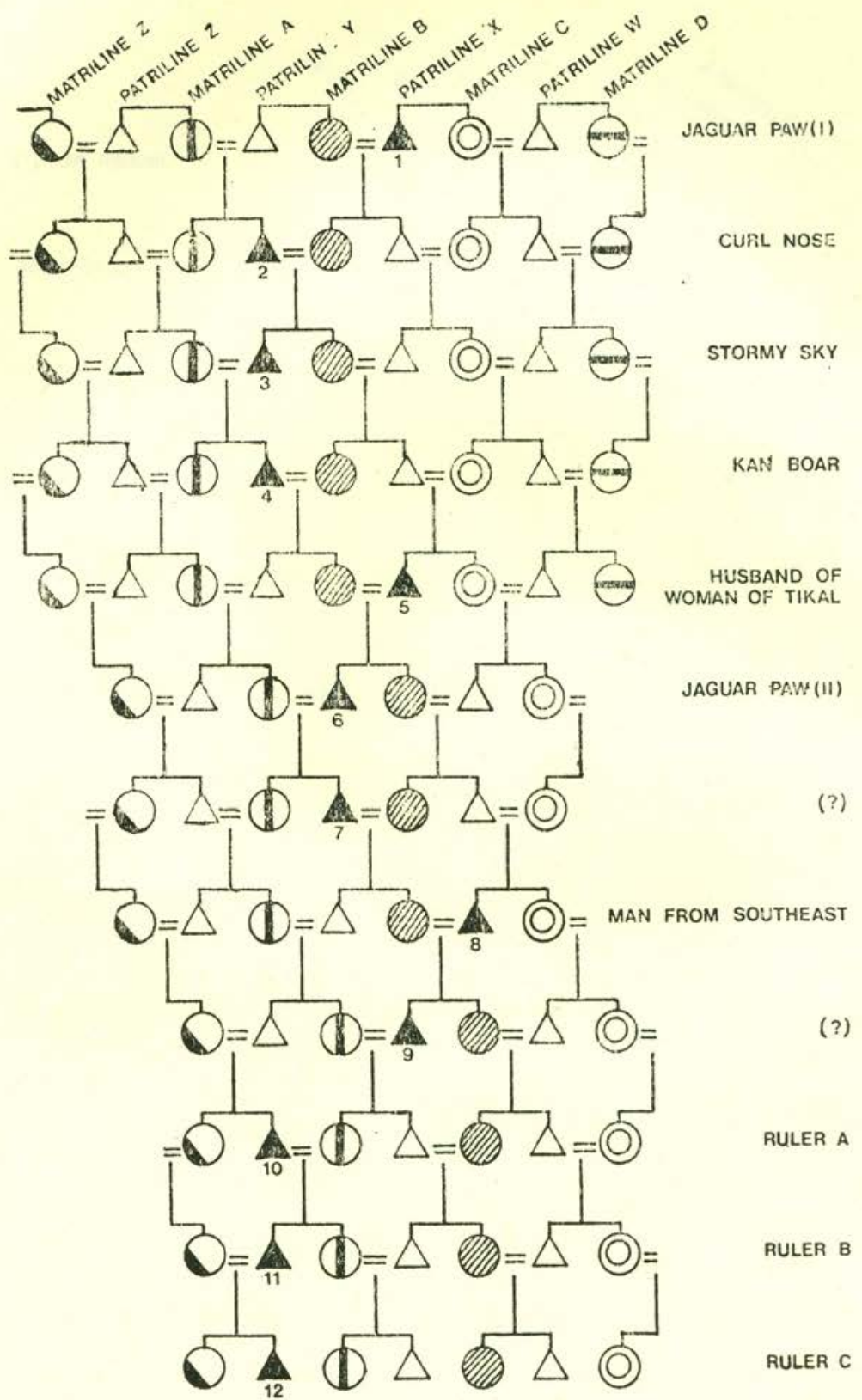

Figure 9. Interpretation of the dynastic succession at Tikal which assumes that Ruler 5 is an outsider, that Ruler 8 is an outsider also, and that the inauguration of Ruler 10 involves the initiation of a new 260 tun cycle in which one of the ruling matrilines is replaced. 


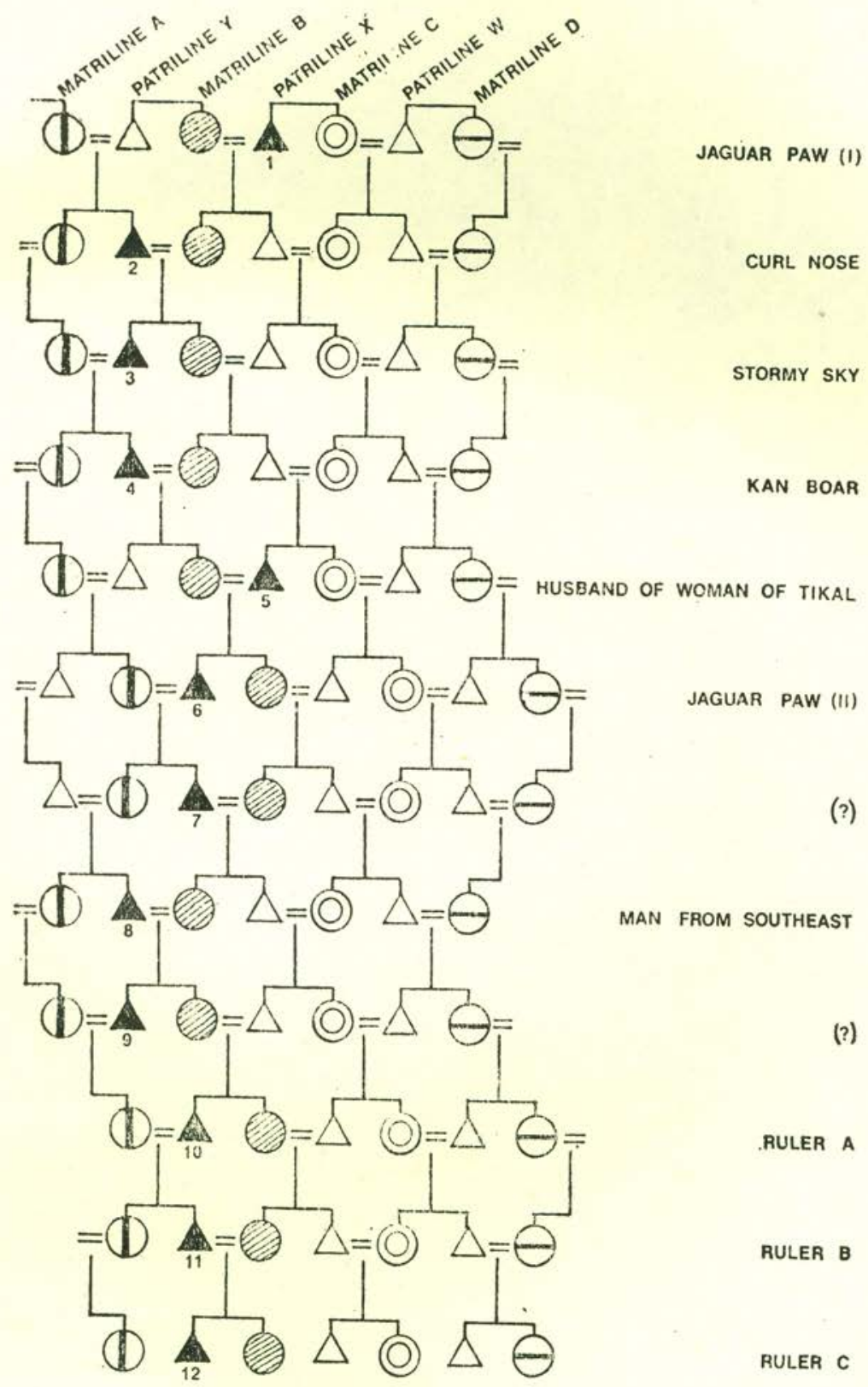

Figure 10. Interpretation of the dynastic succession at Tikal which assumes that Ruler 5 is an outsider, that Ruler 8 is not, and that the inauguration of Ruler 10 is not marked by replacement of either one or both of the ruling patrilines, though it does mark the beginning of a new 260 tun cycle. 